\title{
Learning Increases Intrinsic Excitability of Hippocampal Interneurons
}

\author{
Bridget M. McKay, M. Matthew Oh, and John F. Disterhoft \\ Department of Physiology, Feinberg School of Medicine, Northwestern University, Chicago, Illinois 60611
}

Learning-related intrinsic excitability changes of pyramidal neurons via modulation of the postburst afterhyperpolarization (AHP) have been repeatedly demonstrated in multiple brain regions (especially the hippocampus), after a variety of learning tasks, and in multiple species. While exciting and important, the changes in pyramidal neurons are only a part of the neural circuitry involved in successful learning. For a more complete picture of the dynamic learning-related changes in the neural network, changes in inhibitory circuitry must also be systematically examined and characterized. Here we show in young adult rats and mice that learning the hippocampus-dependent trace eyeblink conditioning task induces enhanced inhibition onto CA1 pyramidal neurons mediated, in part, by an increase in intrinsic excitability of somatostatin-positive inhibitory neurons (SOMs). Furthermore, both CA1 pyramidal and SOM interneurons shared a common cellular mechanism (reduction in SK channel-mediated AHP) that led to the learning-induced increased intrinsic excitability.

\section{Introduction}

Changes in hippocampal neuronal firing rate measured in vivo during learning (McEchron and Disterhoft, 1999; Christian and Thompson, 2003) have led to many ex vivo studies that have focused on identifying and characterizing the cellular mechanisms that underlie them. For example, the increased CA1 pyramidal neuron activity in vivo that modeled the learned delay eyeblink conditioning behavioral response (Berger et al., 1976) is due, in part, to the reduced postburst AHP of CA1 pyramidal neurons (Disterhoft et al., 1986). A more complex neural network change was observed during the acquisition of the hippocampus-dependent trace eyeblink-conditioning task (McEchron and Disterhoft, 1997). Maximal increase in CA1 pyramidal neuron activity was observed on the day when the rabbits exhibited behavioral acquisition of the task (McEchron and Disterhoft, 1997) that ex vivo studies have demonstrated to be mediated in part by reduced postburst AHP of CA1 pyramidal neurons (Disterhoft and Oh, 2006). Notably, additional training to asymptotic behavioral performance led to increases in hippocampal theta (interneuron) activity and suppression of CA1 pyramidal activity during the training trials (McEchron and Disterhoft, 1997). While interneuron function has been shown to be critical for various brain waves that have been linked to successful learning, such as theta oscillations in the hippocampus (Buzsáki, 2002;

Received Aug. 24, 2012; revised Jan. 24, 2013; accepted Feb. 2, 2013.

Author contributions: B.M.M., M.M.O., and J.F.D. designed research; B.M.M. performed research; B.M.M. analyzed data; B.M.M., M.M.O., and J.F.D. wrote the paper.

This work was supported by NIH Grants AG08796 and AG017139 (J.F.D.). We thank Sean Farley and John Linardakis for help with the behavioral experiments. Behavioral assays were performed at the Northwestern University Behavioral Phenotyping Core Facility.

The authors declare no competing financial interests.

Correspondence should be addressed to John F. Disterhoft, Department of Physiology, Feinberg School of Medicine, Northwestern University, Chicago, IL 60611. E-mail: jdisterhoft@northwestern.edu.

DOI:10.1523/JNEUROSCI.4068-12.2013

Copyright $\odot 2013$ the authors $\quad 0270-6474 / 13 / 335499-09 \$ 15.00 / 0$
Klausberger and Somogyi, 2008), possible learning-related intrinsic excitability alterations in these interneurons have not been evaluated. Here, we systematically examined the inhibition onto CA1 pyramidal neurons from young adult rats after they had been trace eyeblink conditioned to identify the cellular mechanism(s) that may alter the inhibitory tone within the hippocampus following successful learning.

\section{Materials and Methods}

Subjects. Young adult (10-16 week old) male rats (F344xBN, Harlan) and GIN mice (FVB-Tg(GadGFP)45704Swn/J, Jackson Laboratory) were used for the experiments. GIN mice breeders were obtained from Jackson Laboratory and bred at Northwestern University's animal vivarium. Animals were handled and housed in small groups with ad libitum access to food and water on a 14/10 h light/dark cycle in accordance with the standards established by the Institutional Animal Care and Use Committee of Northwestern University and the NIH.

Behavior. Animals were trained in trace eyeblink conditioning as previously described for rats (Oh et al., 2009; McKay et al., 2012) and mice (Farley et al., 2011). Headbolts were implanted onto the skulls of anesthetized animals. For both species, headbolts included one wire to ground the animal and two wires that were passed subcutaneously through the upper eyelid of the right eye to record the electromyographic (EMG) activity of the orbicularis oculi muscle. For mice, two additional wires where subcutaneously passed through the periorbital region caudal to the eye to deliver the shock unconditioned stimulus. Animals were allowed 3-7 d to recover after surgery before training began.

The headbolt was connected to a tether so that the animal could freely move about the light- and sound-attenuated conditioning chamber. Training consisted of presentations of two stimuli: a conditioned stimulus (CS) and unconditioned stimulus (US). For rats, the CS was a tone (8 $\mathrm{kHz}, 85 \mathrm{~dB}, 250 \mathrm{~ms}, 5 \mathrm{~ms}$ rise-fall time) and the US was a puff of air to the eye ( $4 \mathrm{psi}$ ). For mice, the CS was a deflection of the whiskers on one side of the face by a comb driven by a piezo strip attached to the tether $(60 \mathrm{~Hz}$, $250 \mu \mathrm{m}$ deflection), and the US was a shock sufficient to cause reliable eyeblinks (0.25-2 mA periorbital square wave shock, $60 \mathrm{~Hz}, 0.5 \mathrm{~ms}$ pulses). Conditioned animals received 30 pairings ( $20-40 \mathrm{~s}$ ITI) of the 

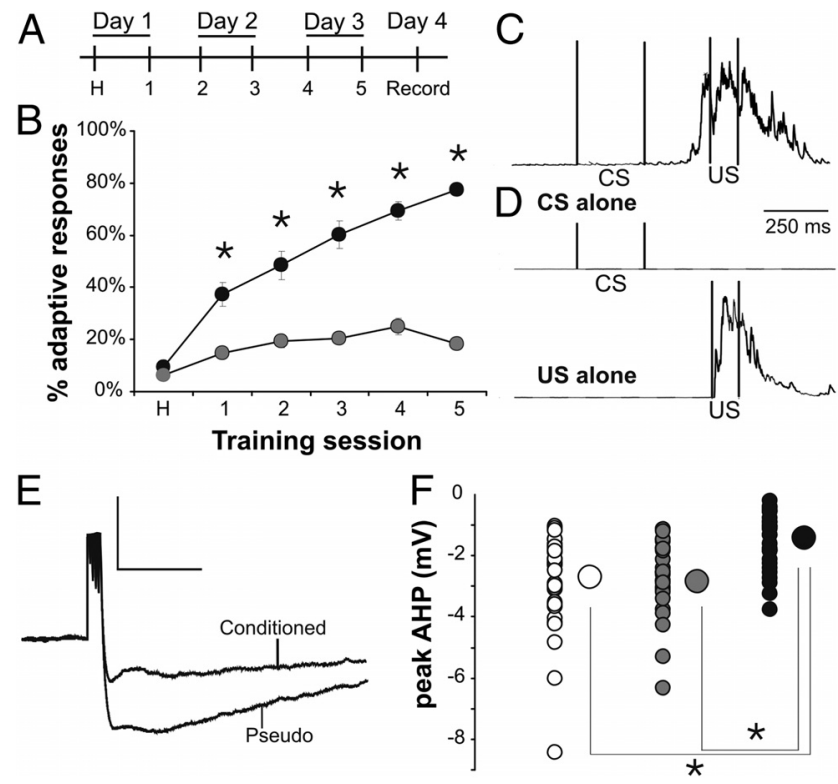

Figure 1. Learning resulted in significantly reduced postburst AHP evoked with direct current injections into the soma of CA1 pyramidal neurons. $A$, Rats were trained twice a day for $3 \mathrm{~d}$, and electrophysiological recordings were made on the fourth day. $\boldsymbol{B}$, Conditioned rats (closed circles; $N=26$ ) exhibited significantly more adaptive responses compared with pseudoconditioned rats (gray circles; $N=21$ ) across the five training sessions ( $r$ mANOVA: $F_{(1,49)}=123.8$, $p<0.0001$; *unpaired $t$ test $p<0.01) . \mathbf{C}, \boldsymbol{D}$, Examples of integrated EMG response are illustrated from a conditioned $(\boldsymbol{C})$ and a pseudoconditioned $(\boldsymbol{D})$ rat. $C$ illustrates an adaptive response to a paired presentation of the tone (CS) and airpuff (US) during session 5. D illustrates the lack of an adaptive response to a CS-alone trial and an US-alone trial from a pseudoconditioned rat during session 5. $\boldsymbol{E}$, Example of postburst AHP traces evoked with direct current injections into CA1 pyramidal neurons from a conditioned and a pseudoconditioned rat. Calibration: $4 \mathrm{mV}, 500 \mathrm{~ms}$. F, The postburst AHP evoked using direct somatic current injections was significantly reduced in CA1 pyramidal neurons from rats that had learned the task as compared with those from pseudo and naive rats $\left(F_{(2,87)}=12.98, p<0.0001\right.$; Fisher's PLSD $p<0.05$ conditioned vs pseudo and naive). Smaller circles are the data points from individual neurons. Larger circles are the group means. Error bars are SEM (obscured by the group mean circles). Open circle, Naive; gray circle, pseudoconditioned; black circle, conditioned. n: naive 32, pseudo 26 , conditioned 32.

CS and US separated by a $250 \mathrm{~ms}$ stimulus-free "trace" interval. Pseudoconditioned animals also received 30 CSs and 30 USs per training session, but the two were explicitly unpaired (10-20 s ITI).

Animals received two training sessions per day for $3 \mathrm{~d}$ (see Figs. 1, 4). The first session on the first training day was a habituation session, during which no stimuli were presented. A computer using custom software written in LabView controlled stimulus presentation procedures and data collection, storage, and analysis routines. Correct responses were eyelid closures during the last $200 \mathrm{~ms}$ of the trace interval. Learning criterion was $60 \%$ correct or adaptive responses in the 30 trials on the last training session.

Electrophysiology. One day after training, 300- $\mu \mathrm{m}$-thick hippocampal slices were prepared using previously described methods (Oh et al., 2009; McKay et al., 2012) in ice-cold artificial CSF (aCSF: consisted of (in mM) 124 $\mathrm{NaCl}, 1.25 \mathrm{NaH}_{2} \mathrm{PO}_{4}, 2.5 \mathrm{KCl}, 26 \mathrm{NaHCO}_{3}, 25$ glucose, $2.4 \mathrm{CaCl}_{2}$, and 2.0 $\mathrm{MgSO}_{4}$, saturated with $95 \% \mathrm{O}_{2} / 5 \% \mathrm{CO}_{2}$ ) and stored at room temperature aCSF for $1 \mathrm{~h}$ before being individually transferred to the recording chamber where the slices were continually perfused with $\sim 30^{\circ} \mathrm{C}$ aCSF.

Cells were visually identified under an upright Zeiss Axioskop with a Hamamatsu digital camera (ORCA-05G) using DIC-IR and fluorescence as appropriate and whole-cell patch clamped. For current-clamp experiments, the internal solution contained the following (in $\mathrm{mM}$ ): 120 $\mathrm{KMeSO}_{4}, 10 \mathrm{KCl}, 10$ HEPES, 10 phosphocreatine sodium salt, 4 ATP magnesium salt, 0.4 GTP sodium salt, and $0.5 \%$ neurobiotin with $\mathrm{pH}$ corrected to 7.35 with $\mathrm{KOH}$ and osmolarity of $285 \pm 5 \mathrm{mOsm}$. For voltageclamp experiments, the internal solution contained the following (in $\mathrm{mm}$ ):
Table 1. Basic membrane properties of included CA1 pyramidal neurons

\begin{tabular}{lccc}
\hline & $\begin{array}{l}\text { Naive } \\
(n=32)\end{array}$ & $\begin{array}{l}\text { Pseudo } \\
(n=26)\end{array}$ & $\begin{array}{l}\text { Conditioned } \\
(n=33)\end{array}$ \\
\hline$V_{\text {rest }}(\mathrm{mV})$ & $-65.5 \pm 0.8$ & $-64.3 \pm 0.7$ & $-63.4 \pm 0.6$ \\
Input resistance $(\mathrm{M} \Omega)$ & $84.2 \pm 6.3$ & $85.4 \pm 4.9$ & $87.8 \pm 7.2$ \\
Sag $(\mathrm{mV})$ & $3.82 \pm 0.43$ & $3.54 \pm 0.26$ & $3.64 \pm 0.32$ \\
AP threshold $(\mathrm{mV})$ & $-50.8 \pm 1.0$ & $-50.8 \pm 1.0$ & $-52.1 \pm 0.7$ \\
AP height $(\mathrm{mV})$ & $89.2 \pm 3.8$ & $90.1 \pm 3.8$ & $88.1 \pm 3.4$ \\
AP half width (ms) & $1.37 \pm 0.07$ & $1.22 \pm 0.08$ & $1.35 \pm 0.08$ \\
Time to spike (ms) & $7.83 \pm 0.49$ & $6.91 \pm 1.74$ & $7.33 \pm 0.49$
\end{tabular}

$V_{\text {rest }}$ is the resting membrane potential immediately after breaking into the cell. Input resistance is calculated as the slope of the IV curve. Sag is the difference between the peak and steady state hyperpolarization in response to an 800 ms current injection. Action potentials were elicited by activation of the Schaffer collaterals. Threshold was measured where the first derivative of the upslope of the trace equals $20 \mathrm{mV} / \mathrm{ms}$. Height is the difference between the baseline and maximal depolarization. Half width is width of the action potential at half of the height. Time to spike is the time from the onset of the stimulus artifact to the peak of the action potential. $n$, Number of neurons.

$130 \mathrm{CsCl}, 4$ ATP magnesium salt, 0.3 GTP sodium salt, 10 HEPES, 5 QX-314, and 10 tris-phosphocreatine with $\mathrm{pH}$ corrected to 7.35 with $\mathrm{CsOH}$ and osmolarity of $295 \pm 5 \mathrm{mOsm}$. Bipolar stimulating electrodes (FHC) were placed in CA1 as required and powered by a Digitimer DS2 isolated stimulator.

Data were collected using a Dagan BVC-700 (current-clamp recordings) or an Axopatch 200B (voltage-clamp recordings) amplifier, digitized, and interfaced to a PC with an Axon Digidata 1322A analog to digital converter, and acquired and analyzed using PClamp 9.2. Leak subtraction was applied to remove capacitive and passive neuronal properties. Junction potential was calculated to be $8 \mathrm{mV}$ and was not adjusted for. Series resistance was monitored frequently and was maximally compensated by the adjustable feedback circuit on the amplifier. For currentclamp experiments, CA1 pyramidal neurons were held with current injection at $-65 \mathrm{mV}$; interneurons were held at $-60 \mathrm{mV}$. For voltageclamp experiments, pyramidal neurons were held at $-60 \mathrm{mV}$ and $2 \mathrm{~mm}$ kyneurinic acid was included in the bath. Drugs were applied as indicated in Results and were obtained from Sigma or Tocris Bioscience.

The experimenter was blind to the training status of the animal throughout data collection and analyses.

Statistics. Statistics were performed using Microsoft Excel (Microsoft Office Pro 2010), SigmaPlot v11, and StatView v5.01. The data are presented as mean \pm SEM. Unless specified, $n$ represents the number of neurons that were recorded from and used for analysis. Differences were evaluated using $t$ tests, one-way ANOVA, and repeated-measures ANOVA (rmANOVA) as appropriate. Fisher's PLSD post hoc tests were used following all ANOVAs showing significance.

\section{Results}

Young-adult (2-4 month old) rats were randomly assigned to one of the behavioral groups [conditioned, pseudoconditioned (pseudo), naive] and trained using previously published trace eyeblink conditioning protocols (Fig. 1A-D) (Oh et al., 2009). As anticipated and consistent with previous reports (Disterhoft and Oh, 2006; Oh et al., 2009), the postburst AHP evoked using direct somatic current injections was significantly reduced in CA1 pyramidal neurons from rats that had learned the task $(-1.41 \pm$ $0.15 \mathrm{mV} ; n=32)$ as compared with those from pseudo $(-2.76 \pm$ $0.24 \mathrm{mV} ; n=26)$ and naive $(-2.82 \pm 0.27 \mathrm{mV} ; n=32)$ rats $\left(F_{(2,87)}=12.98, p<0.0001\right.$; Fisher's PLSD $p<0.05$ conditioned vs pseudo and naive) (Fig. $1 E, F)$. No significant difference was observed in other membrane properties (Table 1). With this direct somatic current injection protocol, learning-related changes in EPSPs and IPSPs could not be systematically examined. Hence, we used bipolar stimulating electrodes placed in the stratum radiatum of the CA1 region to examine the learning-related EPSP and/or IPSP change in CA1 pyramidal neurons.

The hyperpolarization resulting from a $50 \mathrm{~Hz}$ train of synaptically evoked action potentials in normal aCSF is comprised of 
A
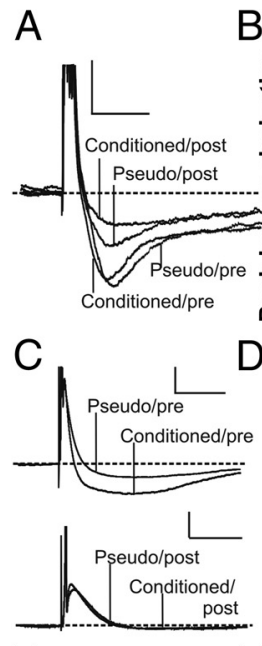

$\mathrm{E}$
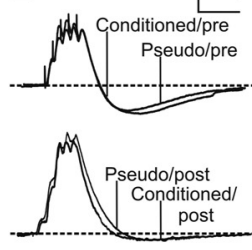

G

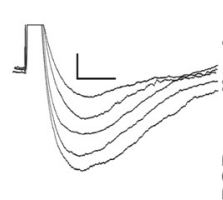

I

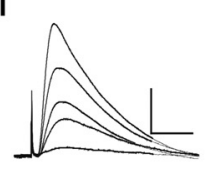

B Five synaptic action potentials

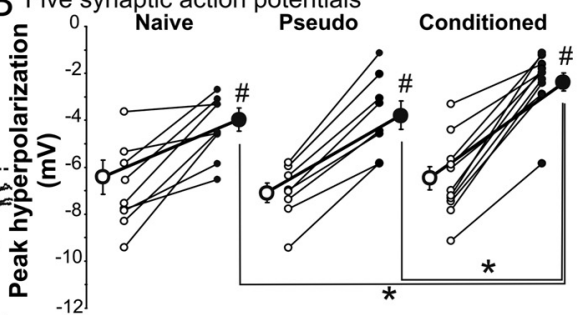

One synaptic action potential

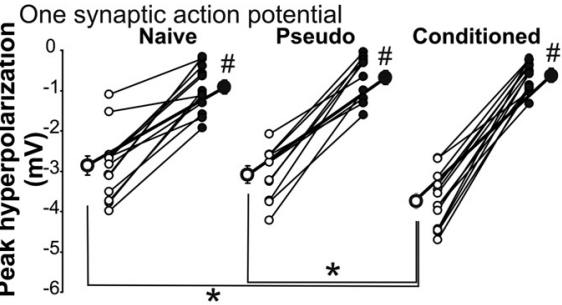

$F^{*}$ Five subthreshold ${ }^{*}$ EPSPs
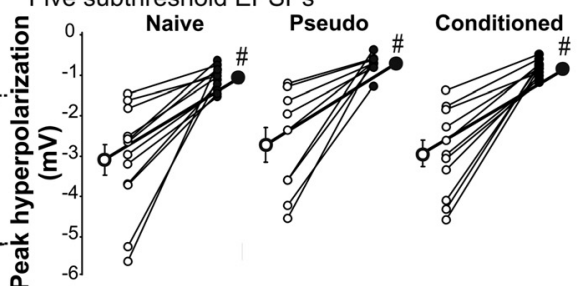

$\mathrm{H}$
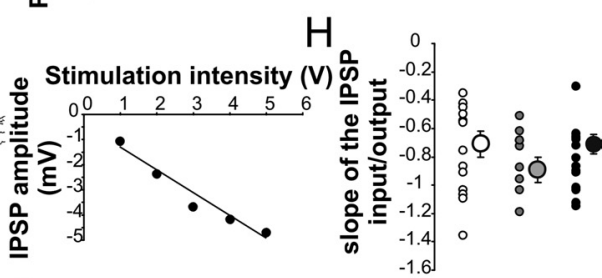

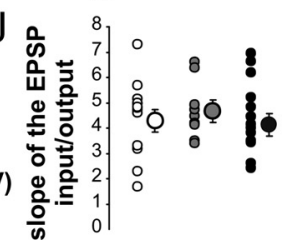

Figure 2. Learning resulted in postburst AHP reduction and IPSP increase in CA1 pyramidal neurons. $A$, Example postburst hyperpolarization traces evoked with $50 \mathrm{~Hz}$ train of five suprathreshold Schaffer collateral stimulation from a CA1 neuron from a conditioned and a pseudoconditioned rats before (Pre) and after (Post) GABA blockers. The action potentials have been truncated to focus on the hyperpolarization. Calibration: $4 \mathrm{mV}, 500 \mathrm{~ms}$. B, Repeated ANOVA revealed significant training $\left(F_{(2,26)}=4.82, p<0.05\right)$ and drug $\left(F_{(1,26)}=79.26, p<0.0001\right)$ effects. Further analysis revealed no significant difference in the postburst hyperpolarization in normal aCSF (pre-GABA ANOVA; $\left.F_{(2,26)}=0.05, p>0.95\right)$. GABA blockers significantly reduced the hyperpolarization in CA1 neurons from all rats ( $"$ paired $t$ test $p<0.05$ ) and unveiled the learning-related postburst AHP reduction in neurons from conditioned rats (post-GABA ANOVA; $F_{(2,26)}=5.77, p<0.01$; ${ }^{*}$ Fisher's PLSD $\left.p<0.05\right)$. Open circles, Pre-GABA blockers; closed circles, post-GABA blockers. $n$ : naive 10, pseudo 9, conditioned 10. C, Example traces of hyperpolarization evoked with single synaptically evoked action potential from CA1 neurons from conditioned and pseudoconditioned rats before (Pre) and after (Post) GABA blockers. Calibration: $5 \mathrm{mV}, 100 \mathrm{~ms}$. D, Repeated ANOVA revealed significant drug $\left(F_{(1,33)}=114.27, p<\right.$ $0.0001)$ and interaction of drug and training $\left(F_{(2,33)}=9.51, p=0.0005\right)$ effects on the IPSP following a single synaptically evoked AP. Further analysis revealed that GABA blockers significantly reduced the IPSP in CA1 neurons from all behavioral groups ( ${ }^{p}$ paired $t$ test $p<0.05$ ) and abolished the learning-related IPSP enlargement observed in normal aCSF (pre-GABA ANOVA: $F_{(2,33)}=6.88, p<0.005$; ${ }^{*}$ Fisher's PLSD $p<0.05$ conditioned vs pseudo and naive; post-GABA ANOVA: $\left.F_{(2,33)}=1.35, p>0.25\right) . n$ : naive 13 , pseudo 10 , conditioned 13. $\boldsymbol{E}$, llustrated are example traces evoked with $50 \mathrm{~Hz}$ trains of five subthreshold Schaffer collateral stimulation in CA1 neurons from conditioned and pseudoconditioned rats before (Pre) and after (Post) GABA blockers. Calibration: $3 \mathrm{mV}, 100 \mathrm{~ms}$. $\boldsymbol{F}$, Repeated ANOVA revealed significant drug $\left(F_{(1,29)}=\right.$ $6.88, p<0.005)$ and interaction of drug and training $\left(F_{(2,29)}=4.66, p<0.05\right)$ effects on the IPSP following a $50 \mathrm{~Hz}$ train of subthreshold EPSPs. Further analysis revealed that GABA blockers

Table 2. Properties of EPSPs measured from CA1 pyramidal neurons

\begin{tabular}{llcl}
\hline & $\begin{array}{l}\text { Naive } \\
(n=10)\end{array}$ & \multicolumn{1}{l}{$\begin{array}{l}\text { Pseudo } \\
(n=9)\end{array}$} & \multicolumn{1}{l}{$\begin{array}{l}\text { Conditioned } \\
(n=10)\end{array}$} \\
\hline Input/output & $4.42 \pm 0.52$ & $4.71 \pm 0.38$ & $4.68 \pm 0.49$ \\
EPSP rise slope & $0.38 \pm 0.03$ & $0.38 \pm 0.04$ & $0.39 \pm 0.03$ \\
EPSP summation (mV*s) & $8.55 \pm 1.01$ & $10.64 \pm 1.26$ & $9.82 \pm 1.02$
\end{tabular}

EPSP properties were recorded in the presence of GABA blockers. Input/output was measured as the slope of the line of the normalized stimulation intensity and the amplitude of the EPSP. EPSP rise slope is the rise slope of the largest subthreshold EPSP. EPSP summation is measured as the area of five subthreshold EPSPs delivered at $50 \mathrm{~Hz}$ from stimulation initiation to return to baseline membrane potential. None of these measures were significantly altered by learning. $n$, Number of neurons.
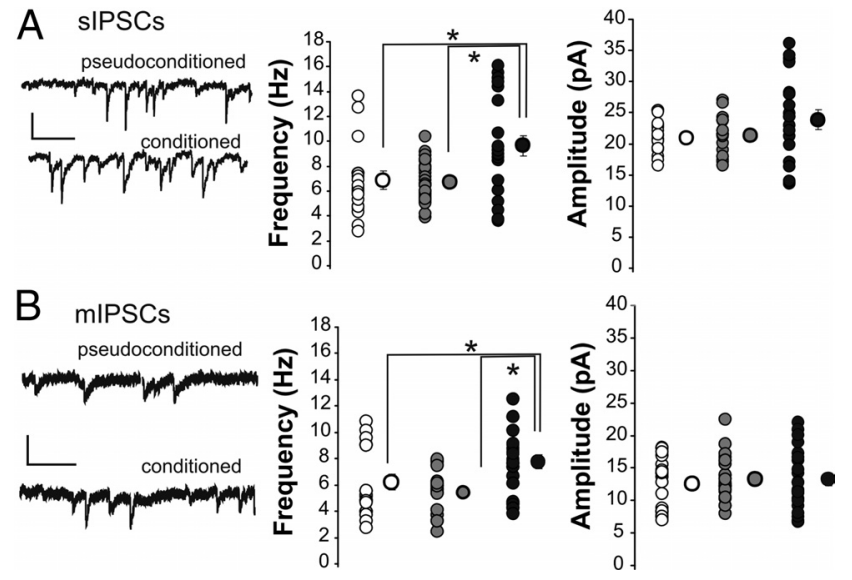

Figure 3. The frequency of spontaneous and miniature IPSCs is increased onto pyramidal neurons from conditioned rats compared with controls. $A$, The frequency, but not amplitude, of SIPSCs is increased onto CA1 pyramidal neurons of conditioned rats (closed circles) compared with naive (clear circles) and pseudoconditioned rats (gray circles). $n$ : naive 20, pseudo 27, conditioned 22. Calibration: 20 pA, $250 \mathrm{~ms}$. $\boldsymbol{B}$, The frequency, but not amplitude, of mIPSCs (recorded in the presence of $100 \mathrm{~nm}$ TTX) is increased onto CA1 pyramidal neurons of conditioned rats compared with naive and pseudoconditioned rats. Calibration: 20 pA, $250 \mathrm{~ms} . n$ : naive 18, pseudo 19, conditioned 19. Note: *Fischer's PLSD $p<0.05$. Smaller circles are the data points from individual neurons. Larger circles are the group means. In some instances, the SEM of each group is smaller than the size of the circle that represents the group mean data.

both postburst AHP and IPSP. Therefore, we performed a series of recordings to isolate the postburst AHP by blocking the IPSP with GABAergic blockers [post-GABA: $5 \mu \mathrm{M}$ SR95531 (GABA $\left.{ }_{\mathrm{A}}\right)$ and $10 \mu \mathrm{M} \mathrm{SCH} 50911\left(\mathrm{GABA}_{\mathrm{B}}\right)$ ] added to the aCSF after the initial postburst hyperpolarization was recorded in normal aCSF (pre-GABA). Repeated ANOVA revealed a significant training $\left(F_{(2,26)}=4.82, p<0.05\right)$ and drug (pre- vs post-GABA: $F_{(1,26)}=$ 79.26, $p<0.0001)$ effects, but no significant training by drug interaction. Further analysis revealed that the initial baseline postburst hyperpolarization evoked with $50 \mathrm{~Hz}$ train of suprathreshold stimulation (pre-GABA) was nearly identical in the CA1 pyramidal neurons from all three groups (Fig. $2 A, B$ ) in normal

significantly reduced the IPSP in CA1 neurons from all behavioral groups ("paired $t$ test $p<$ 0.05 ). No significant IPSP differences were observed between groups either before or after GABA blockers. n: naive 9, pseudo 9, conditioned 11. G-J, IPSPs and EPSPs were evoked using fixed voltage stimulation with a Digitimer-isolated stimulator and a stimulating electrode placed in the stratum radiatum. G, Illustrated is an example of the evoked IPSPs and the resulting input/output slope determined by a linear regression of the IPSP amplitude and the fixed voltage stimulation. Calibration: $100 \mathrm{~ms}, 1 \mathrm{mV}$. H, J, No significant differences in the input/ output slopes were observed for either the IPSP or the EPSP between the training groups (naive-white, $n=13$; pseudo—gray, $n=9$; conditioned—black, $n=14$ ). I, Illustrated is an example of the evoked EPSPs in the presence of GABA blockers and the resulting input/ output slope determined by a linear regression of the EPSP amplitude and the fixed voltage stimulation. Calibration: $100 \mathrm{~ms}, 5 \mathrm{mV}$. 
Table 3. Properties of spontaneous and miniature IPSCs measured from CA1 pyramidal neurons

\begin{tabular}{|c|c|c|c|c|c|c|}
\hline & \multicolumn{3}{|l|}{ sIPSCS } & \multicolumn{3}{|l|}{$\mathrm{mIPSCs}$} \\
\hline & $\begin{array}{l}\text { Naive } \\
(n=20)\end{array}$ & $\begin{array}{l}\text { Pseudo } \\
(n=27)\end{array}$ & $\begin{array}{l}\text { Conditioned } \\
(n=22)\end{array}$ & $\begin{array}{l}\text { Naive } \\
(n=18)\end{array}$ & $\begin{array}{l}\text { Pseudo } \\
(n=19)\end{array}$ & $\begin{array}{l}\text { Conditioned } \\
(n=19)\end{array}$ \\
\hline Amplitude (pA) & $18.25 \pm 1.37$ & $21.17 \pm 0.97$ & $20.48 \pm 1.53$ & $10.45 \pm 0.29$ & $10.67 \pm 0.36$ & $11.94 \pm 0.82$ \\
\hline Rise & $3.53 \pm 0.16$ & $3.87 \pm 0.15$ & $4.15 \pm 0.18$ & $1.97 \pm 0.06$ & $1.89 \pm 0.08$ & $2.12 \pm 0.09$ \\
\hline Decay & $5.84 \pm 0.29$ & $6.27 \pm 0.33$ & $5.83 \pm 0.30$ & $3.23 \pm 0.16$ & $2.88 \pm 0.17$ & $3.33 \pm 0.24$ \\
\hline
\end{tabular}

Spontaneous and miniature IPSCs were recorded onto CA1 pyramidal neurons. mIPSCS were recorded in the presence of $500 \mathrm{nM}$ TTX. While there was a significant difference in the number of both IPSCs and EPSC (see Fig. 3 ), there was no significant difference in the amplitude, area, rise, or decay. $n$, Number of neurons.

aCSF (pre-GABA ANOVA: $F_{(2,26)}=0.05, p>0.95$ ). More importantly, the learning-related synaptically evoked postburst AHP reduction was unmasked by bath application of GABA blockers (post-GABA ANOVA: $F_{(2,26)}=5.77, p<0.01$; Fisher's PLSD $p<$ 0.05 conditioned vs pseudo and naive) (Fig. $2 B$ ). As expected, GABAergic blockers had no impact on the postburst AHP evoked using direct somatic current injections (rmANOVA; $F_{(1,26)}=0.50$, $p>0.48$ ). Hence, the postburst AHP of CA1 pyramidal neurons, whether somatically or synaptically evoked, is reduced by successful learning and is a cellular mechanism for learning. Furthermore, these data strongly suggest that inhibition onto CA1 pyramidal neurons was increased following successful learning.

The learning-induced increase in inhibition could be due to changes in the CA1 pyramidal neuron itself, or it could be due to changes in the activity of interneurons. To identify the locus of the inhibition change, we systematically examined the potential source of the learning-induced inhibition increase.

First we examined the hyperpolarization following a single synaptically evoked action potential, which is insufficient to evoke a robust slow postburst AHP (Wu et al., 2004). A single suprathreshold Schaffer collateral stimulation evoked a significantly larger hyperpolarization in CA1 pyramidal neurons from rats that learned the trace eyeblink conditioning task as compared with those from pseudo and naive rats in normal aCSF (preGABA ANOVA: $F_{(2,33)}=6.88, p<0.005$; Fisher's PLSD $p<0.05$ conditioned vs pseudo and naive) (Fig. $2 C, D$ ). There was no difference between groups in the threshold, height, or half-width of the synaptically evoked action potential (Table 1). Bath application of GABAergic blockers significantly reduced the single AP-evoked hyperpolarization in CA1 neurons from all three behavioral groups (rmANOVA pre- vs post-GABA: $F_{(1,33)}=$ 374.21; $p<0.0001$ ), which abolished the learning-induced hyperpolarization increase and equalized the single AP-evoked hyperpolarization (post-GABA ANOVA: $F_{(2,33)}=1.35, p>0.25$ ) (Fig. 2D).

We next determined whether the learning-induced IPSP increase required action potentials from CA1 pyramidal neurons. To test this hypothesis, subthreshold EPSPs were evoked using a bipolar stimulating electrode in the stratum radiatum. A previous report demonstrated that a learning-related increase in EPSP in the CA1 region was observed immediately after (within $1 \mathrm{~h}$ ) but not $24 \mathrm{~h}$ after animals reached optimal level of behavioral performance on the trace eyeblink conditioning task (Power et al., 1997). Similarly, we observed no significant EPSP difference between the groups in either normal aCSF or in the presence of GABA blockers $24 \mathrm{~h}$ after the last training session in the input/ output slope, EPSP rise slope, and degree of EPSP summation (Table 2; Fig. 2G-J). Hence, a $50 \mathrm{~Hz}$ train of five subthreshold EPSPs was elicited with the amplitude of the first EPSP set at $3 \mathrm{mV}$ (Fig. 2E). The hyperpolarization following the EPSP trains was not altered by learning (rmANOVA: $F_{(2,26)}=0.41, p>0.67$ ) either before or after GABAergic blockers were added to the aCSF
(Fig. 2 F). GABAergic blockers did abolish the hyperpolarization in CA1 neurons from all three behavioral groups (rmANOVA pre- vs post-GABA: $\left.F_{(2,26)}=4.66, p<0.05\right)$, suggesting that the subthreshold EPSP-evoked hyperpolarization was largely due to activity of interneurons, but not those which contributed to the learning-induced IPSP increase.

These experiments strongly suggested that increased activity of an inhibitory circuit underlies the learning-induced IPSP increase observed in CA1 pyramidal neurons. However, it is also possible that the learning-induced inhibition increase was due to a change in the CA1 pyramidal neurons themselves, such as increased amount of GABA receptors. To address this latter hypothesis, we conducted a series of whole-cell voltage-clamp experiments and measured spontaneous and miniature IPSCs onto CA1 pyramidal neurons. Learning resulted in increased frequency, but not amplitude, of both spontaneous (Fig. 3A; $\left.F_{(2,66)}=6.81, p<0.005\right)$ and miniature (Fig. $3 B ; F_{(2,53)}=5.46$, $p<0.01)$ IPSCs. No significant difference between groups was observed in the amplitude, area, rise time, or decay time of either IPSC type (Table 3). The series resistance was closely monitored, and also did not differ between groups. The increase in frequency of both the spontaneous and miniature IPSCs suggests that the learning-induced inhibitory increase was presynaptic to CA1 pyramidal neurons and that learning induced an increase in interneuron baseline activity caused by altered intrinsic excitability.

These electrophysiology data from CA1 hippocampal pyramidal neurons strongly suggested that inhibition onto CA1 pyramidal neurons is increased following learning. However, direct evidence that learning induced a change in interneuron function was lacking. Hence, we examined the intrinsic membrane properties of interneurons in the CA1 region following trace eyeblink conditioning.

There are numerous types of interneurons based on axonal morphology, neurochemical expression, and firing properties (Freund and Buzsáki, 1996; McBain and Fisahn, 2001; Markram et al., 2004). Hence, we took advantage of a transgenic mouse line (GIN mice) that was engineered to specifically express enhanced green fluorescent protein (EGFP) in a subset of their somatostatin positive interneurons (Oliva et al., 2000) to examine our hypothesis that learning alters intrinsic excitability of inhibitory interneurons. The somatostatinpositive EGFP interneurons found in the stratum oriens of the CA1 region of GIN mice have dendritic and axonal morphology similar to that described for a well studied and characterized class of interneurons, the oriens-lacunosum moleculare (O-LM) interneurons (Oliva et al., 2000; Minneci et al., 2007). However, the firing pattern of these somatostatin-positive EGFP interneurons is heterogeneous, including patterns similar to that observed for O-LM interneurons (Minneci et al., 2007), and thus, these EGFP somatostatin-positive interneu- 

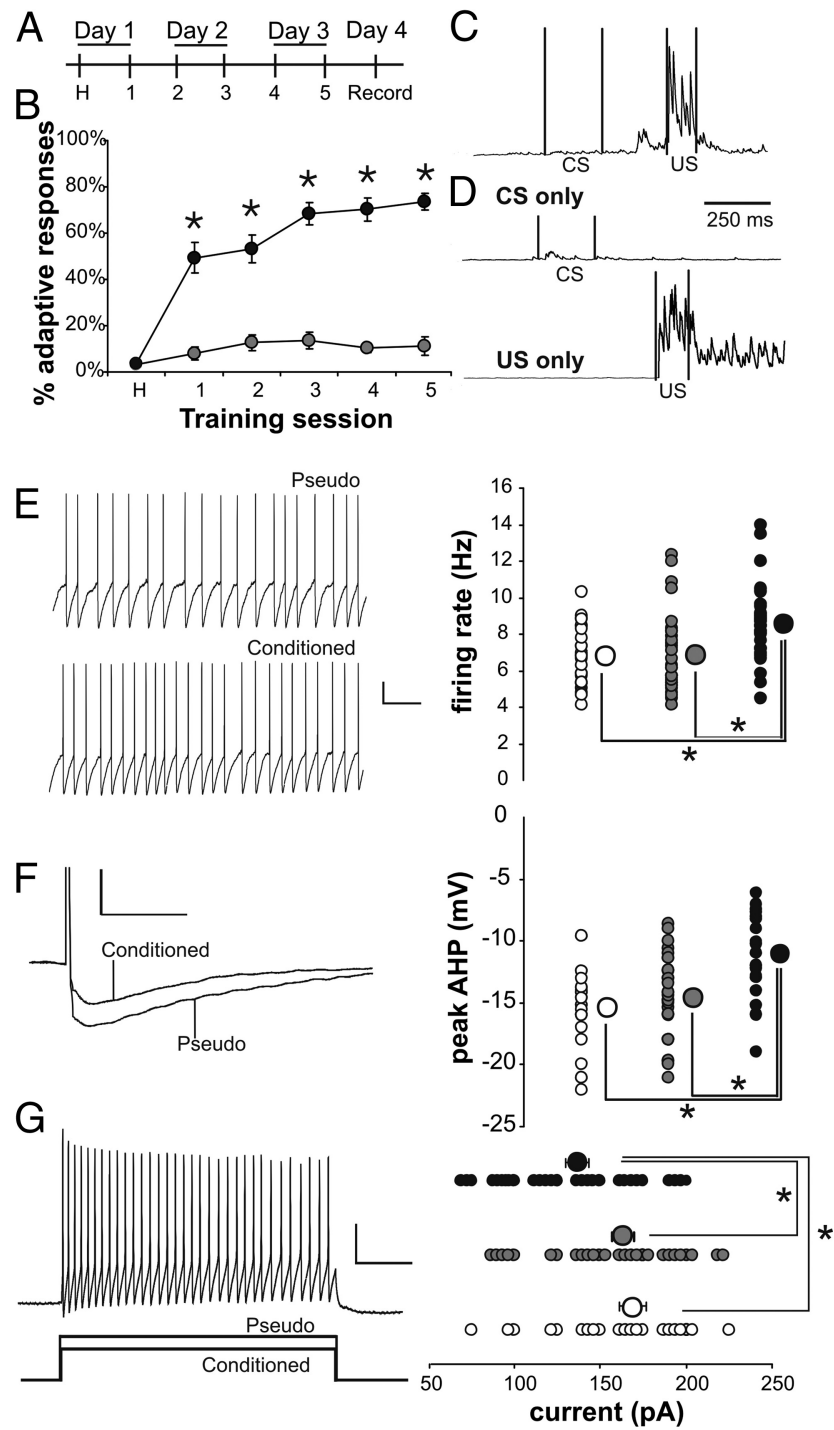

Figure 4. Intrinsic excitability is increased in SOMs from trained mice compared with controls. $\boldsymbol{A}$, Mice were trained twice a day for $3 \mathrm{~d}$, and electrophysiological recordings were made on the fourth day. $\boldsymbol{B}$, Conditioned mice (closed circles; $N=29$ ) exhibited significantly more adaptive responses compared with pseudoconditioned mice (open circles; $N=24$ ) (rmANOVA: $F_{(1,51)}=117.4, p<0.0001$; * unpaired $t$ test $\left.p<0.01\right)$. C, D, Examples of integrated EMG response are illustrated from a conditioned $(\boldsymbol{C})$ and a pseudoconditioned $(\boldsymbol{D})$ mouse. Cillustrates an adaptive response to a paired presentation of the whisker vibration (CS) and periorbital shock (US) during session 5.D illustrates the lack of an adaptive response to a CS-alone trial and an US-alone trial from a pseudoconditioned mouse during session 5. $\boldsymbol{E}$, Learning resulted in significantly increased spontaneous firing rate at resting membrane potential in SOM neurons. Conditioned, black circle; pseudoconditioned, gray circle; naive, open circle. Calibration: $10 \mathrm{mV}$, $500 \mathrm{~ms}$. $\boldsymbol{F}$, The AHP following a single action potential is significantly reduced in SOMs from conditioned mice compared with controls. Calibration: $10 \mathrm{mV}, 50 \mathrm{~ms}$. G, The current required to elicit 20 action potentials in $1 \mathrm{~s}$ was significantly less in cells from conditioned animals compared with controls. Calibration: 20 mV, 150 pA, 200 ms. $n$ : naive 25, pseudo 32, conditioned 32. Note: *Fischer's PLSD $p<0.05$. Smaller circles are the data points from individual neurons. Larger circles are the group means. In some instances, the SEM of each group is smaller than the size of the circle that represents the group mean data.

rons found in the stratum oriens of the CA1 region are referred to in this report as SOMs.

The GIN transgenic mice were randomly assigned to one of the behavioral groups (conditioned, pseudo, naive) and trace eyeblink conditioned (Farley et al., 2011) (Fig. 4A-D). Learningrelated postburst AHP reductions have previously been demonstrated in mice CA1 pyramidal neurons (Kaczorowski et al.,
Table 4. Basic membrane properties of included interneurons

\begin{tabular}{lrrr}
\hline & Naive $(n=25)$ & Pseudo $(n=32)$ & \multicolumn{1}{c}{$\begin{array}{l}\text { Conditioned } \\
(n=32)\end{array}$} \\
\hline$V_{\text {rest }}(\mathrm{mV})$ & $-49.82 \pm 1.87$ & $-49.20 \pm 1.65$ & $-50.57 \pm 1.26$ \\
Input resistance $(\mathrm{M} \Omega)$ & $249.3 \pm 42.6$ & $224.1 \pm 35.2$ & $260.7 \pm 51.8$ \\
AP threshold $(\mathrm{mV})$ & $-44.08 \pm 2.33$ & $-41.29 \pm 1.15$ & $-43.14 \pm 1.52$ \\
AP height $(\mathrm{mV})$ & $70.04 \pm 3.18$ & $71.10 \pm 5.32$ & $70.96 \pm 3.29$ \\
AP half width (ms) & $1.27 \pm 0.11$ & $1.39 \pm 0.10$ & $1.30 \pm 0.13$ \\
Sag (mV) & $2.79 \pm 0.16$ & $2.64 \pm 0.22$ & $2.57 \pm 0.19$ \\
\hline
\end{tabular}

$V_{\text {rest }}$ is the resting membrane potential immediately after breaking into the cell. Input resistance is calculated as the slope of the IV curve. Action potentials were elicited by current injection through the recording electrode. Threshold was measured where the first derivative of the upslope of the trace equals $20 \mathrm{mV} / \mathrm{ms}$. Height is the difference between the baseline and maximal depolarization. Half width is the width of the action potential at half of the height. Sag was measured as the difference in the peak versus the steady state hyperpolarization to a $-100 \mathrm{pA}$ current injection from a holding potential of $-60 \mathrm{mV}$. $n$, Number of neurons.

2011), as in the rat. Hence, whole-cell current-clamp recordings were made from visually identified SOMs.

SOMs from trained mice had significantly elevated spontaneous firing rate at their resting membrane potential $(8.56 \pm 0.36$ $\mathrm{Hz} ; n=32)$ compared with cells from pseudo $(6.86 \pm 0.38 \mathrm{~Hz}$; $n=32)$ or naive $(6.81 \pm 0.33 \mathrm{~Hz} ; n=25)$ animals (Fig. $4 E$; $F_{(2,86)}=7.83, p<0.001$; Fisher's PLSD $p<0.05$ conditioned vs pseudo and naive). The depolarizing current necessary to elicit 20 action potentials in $1 \mathrm{~s}$ from $-60 \mathrm{mV}$ holding potential was also significantly reduced in cells from mice that learned the task $(136.7 \pm 6.82 \mathrm{pA} ; n=32)$ as compared with those from pseudo $(163.3 \pm 6.45 \mathrm{pA} ; n=32)$ and naive $(169.0 \pm 7.81 \mathrm{pA} ; n=25)$ mice (Fig. $4 F ; F_{(2,86)}=6.16, p<0.005$; Fisher's PLSD $p<0.05$ conditioned vs pseudo and naive). In addition, the peak hyperpolarization following a single action potential was significantly reduced in cells from mice that learned $(-11.09 \pm 0.56 \mathrm{mV} ; n=$ $32)$ as compared with those from pseudo $(-14.66 \pm 0.59 \mathrm{mV}$; $n=32)$ and naive $(-15.40 \pm 0.63 \mathrm{mV} ; n=25)$ (Fig. $4 G ; F_{(2,86)}=$ $15.20, p<0.0001$; Fisher's PLSD $p<0.05$ conditioned vs pseudo and naive). There was no difference in the resting membrane potential, input resistance, sag, or action potential measurements between groups (Table 4 ).

The learning-induced increase in intrinsic excitability of these SOM interneurons raised an intriguing hypothesis. The O-LM neurons, which express somatostatin, have an apaminsensitive calcium-dependent AHP (Zhang and McBain, 1995). Hippocampal pyramidal neurons express SK channel mediated, apamin-sensitive medium postburst AHP (Stocker et al., 1999; Oh et al., 2000) that is reduced by hippocampusdependent learning (Disterhoft and Oh, 2006; McKay et al., 2012). Hence, could the cellular mechanism that underlies learning-related changes in interneurons be the same one used by hippocampal pyramidal neurons to alter their intrinsic excitability, alteration of the calcium-dependent AHP?

To address this hypothesis, we performed a series of occlusion experiments on SOMs using the SK channel agonist $(10 \mu \mathrm{M}$ NS309) and antagonist (500 nM apamin) (McKay et al., 2012). NS309 significantly increased the AHP and accommodation in cells from all groups and especially in the interneurons from trained mice, abolishing the learning-mediated differences (Fig. $5 C, D)$. Conversely, apamin had no significant effect on the AHP or accommodation in cells from mice that learned the trace eyeblink conditioning task, demonstrating that learning reduced the apamin-mediated increased excitability (Fig. $5 A, B$ ), but significantly reduced the AHP and accommodation in neurons from pseudoconditioned and naive mice. After apamin, there was no significant difference between groups in the size of the AHP or in the degree of accommodation (Fig. $5 A, B$ ). Together, the NS309 
A apamin
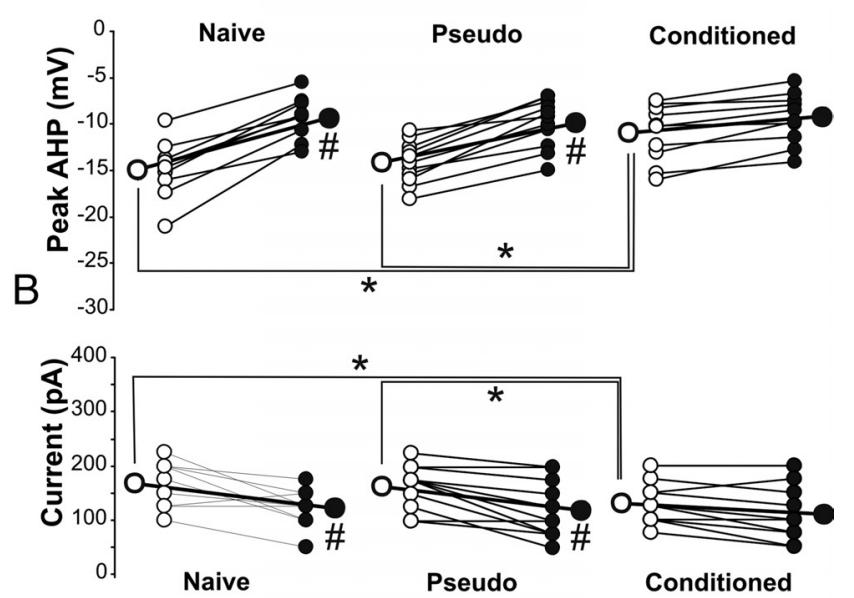

C NS309
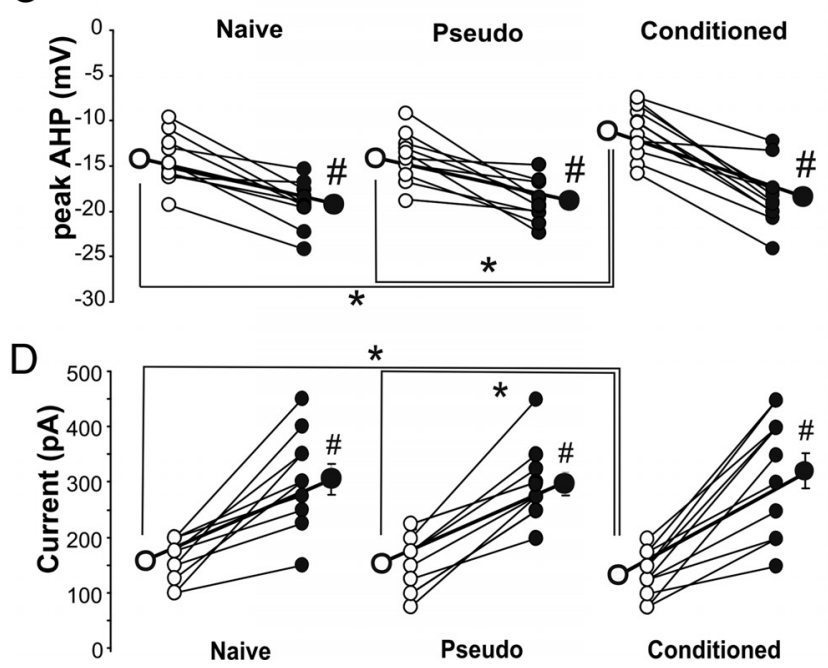

Figure 5. Learning-related increased intrinsic excitability of SOM neurons is mediated by reductions in the apamin-sensitive AHP. $\boldsymbol{A}$, Repeated ANOVA revealed significant training $\left(F_{(2,25)}=5.96, p<0.001\right)$ and apamin $\left(F_{(1,25)}=3.84, p<0.05\right)$ effects on the peak AHP. Before apamin application, the peak AHP was significantly reduced in SOM neurons from conditioned mice (pre-apamin ANOVA: $F_{(2,25)}=5.77, p<0.01$; ${ }^{*}$ Fischer's PLSD $p<0.05$ ). Apamin $(500 \mathrm{~nm})$ reduced the AHP following a single action potential in cells from pseudoconditioned and naive animals, but not from conditioned animals ( $\#$ paired t tests $p<0.05$ ). After apamin there was no difference between groups in the size of the AHP. $\boldsymbol{B}$, Repeated ANOVA revealed significant training $\left(F_{(2,25)}=5.76, p<0.01\right)$ and apamin $\left(F_{(1,25)}=4.17, p<0.05\right)$ effects on the current necessary to elicit 20 action potentials (APs) in $1 \mathrm{~s}$. Before apamin application, significantly less current was needed in $\mathrm{SOM}$ neurons from conditioned mice to elicit 20 APs (pre-apamin ANOVA: $F_{(2,25)}=4.00, p<0.05 ;{ }^{*}$ Fischer's PLSD $\left.p<0.05\right)$. Apamin $(500 \mathrm{~nm})$ decreased the amount of current required to elicit $20 \mathrm{APs}$ in cells from pseudoconditioned and naive animals, but not from conditioned animals ( ${ }^{\text {paired }} t$ tests $p<0.05$ ). After apamin, there was no difference between groups in the degree of accommodation. $n$ : naive 9 , pseudo 10 , conditioned 10. C, Repeated ANOVA revealed significant training $\left(F_{(2,25)}=4.22, p<0.05\right)$ and $\operatorname{NS} 309\left(F_{(1,25)}=4.59, p<0.05\right)$ effects on the peak AHP. Before NS309 application, the peak AHP was significantly reduced in SOM neurons from conditioned mice (pre-NS309 ANOVA: $F_{(2,25)}=3.45, p<0.05$; *Fischer's PLSD $\left.p<0.05\right)$. Application of $10 \mu \mathrm{M} \mathrm{NS} 309$ increased the size of the AHP in neurons from all training groups ( paired $t$ tests $p<0.005$ ) and abolished the learning-related AHP reduction. $\boldsymbol{D}$, Repeated ANOVA revealed significant training $\left(F_{(2,27)}=\right.$ $4.90, p<0.05)$ and NS309 $\left(F_{(1,27)}=4.24, p<0.05\right)$ effects on the current necessary to elicit 20 APs in $1 \mathrm{~s}$. Before $10 \mu \mathrm{m}$ NS309 application, significantly less current was needed in SOM neurons from conditioned mice to elicit 20 APs (pre-NS309 ANOVA: $F_{(2,27)}=5.27, p<0.05$; *Fischer's PLSD $p<0.05)$. NS309 $(10 \mu \mathrm{M})$ increased the amount of current required to elicit 20 APs in neurons from all training groups ( $"$ paired $t$ tests $p<0.05$ ). After NS309, there was no difference between groups in the amount of current required to elicit 20 action potentials. $n$ : naive 8 , pseudo 11, conditioned 11. Open circle, Predrug; filled circle, postdrug. and apamin data suggest that decreased SK current in part mediates the learning-induced increase in intrinsic excitability of the SOMs.

\section{Discussion}

Our present findings are the first to demonstrate that intrinsic excitability is increased in the SOM inhibitory interneurons as well as in principal neurons following successful learning and is mediated by reductions in calcium-dependent potassium currents in both neuron types. Other currents may also contribute to the learning-related increased excitability of SOM interneurons. For example, holding current and $I_{\mathrm{h}}$ have been shown to impact the firing rate observed in O-LM interneurons (Maccaferri and McBain, 1996). However, neither the holding current nor $I_{\mathrm{h}}$ are likely sources of the increased intrinsic excitability of SOMs, since all biophysical measurements were conducted at the same holding and resting membrane potentials and no significant difference was observed in the sag measurements, which reflect activity of $I_{\mathrm{h}}$ (Poolos et al., 2002). Hence the pharmacological occlusion experiments with the apamin-sensitive SK channel activator and antagonist in SOMs provide compelling evidence that the learning-related postburst AHP reduction is a common-shared cellular mechanism that mediates the increase in intrinsic neuronal excitability and, in part, underlies learning in CA1 pyramidal and SOM neurons.

But can altering the postburst AHP influence learning? $\mathrm{Nu}-$ merous studies with aged animals have demonstrated that agerelated learning deficits are reversed with pharmacological manipulations that reduce the normally enlarged postburst AHP of CA1 pyramidal neurons observed in aged animals (Disterhoft and Oh, 2006). In young adults, activation of the CREB pathway has been shown to increase neuronal excitability by reducing the currents that underlie the postburst AHP (Lopez de Armentia et al., 2007; Zhou et al., 2009), and those same neurons are preferentially integrated in the neural circuitry that underlie learning (Han et al., 2007, 2009; Zhou et al., 2009). Recently, enlarging the apamin-sensitive SK channel-mediated postburst AHP in CA1 neurons with NS309 (SK channel activator) directly injected into the dorsal hippocampus caused learning deficits in young adult rats (McKay et al., 2012). Hence, modulating the postburst AHP does impact learning. Note that the NS309 enhanced the SK currents in both CA1 principal neurons and interneurons, an important consideration for the findings being reported here.

To date, studies of altered excitability during learning have focused on its occurrence in principal neurons in the brain regions under study (Disterhoft and Oh, 2006; Zhou et al., 2009). Interestingly, several studies have suggested that markers and activity of interneurons are increased with learning in the barrel cortex (Urban-Ciecko et al., 2010) and olfactory cortex (Brosh and Barkai, 2009). In addition, transgenic mice with altered interneuron function displayed impaired learning on hippocampus-dependent tasks (Fuchs et al., 2007; Cui et al., 2008). However, the possibility that increased inhibitory drive, mediated by an increase in intrinsic excitability of interneurons, has not been explored as a critical cellular mechanism for learning. Hence, the present study builds upon a growing body of literature suggesting that increases in inhibition are a common and important mechanism of learning and memory.

But what role do interneurons have during learning and/or memory formation? It has been suggested that increased hippocampal pyramidal activity is necessary for initial learning, but little activity is needed after memory formation and after 
storage has occurred in the neocortical regions (Maviel et al., 2004); i.e., increased inhibition follows changes in excitation. This exact pattern of hippocampal change was observed in vivo as rabbits learned trace eyeblink conditioning (McEchron and Disterhoft, 1997). During the earliest stages of learning, the activity of pyramidal neurons was increased while that of interneurons was decreased. Later, after the animals had acquired the task, the firing rate of interneurons was increased (McEchron and Disterhoft, 1997). Further support is provided by evidence that changes in synaptic contacts onto hippocampal interneurons occur as memory for the hidden platform location is being formed (Ruediger et al., 2011), and that experience-dependent increase in inhibitory synapses onto pyramidal neurons is maintained for days after the initial experience while the change in excitatory synapses is short lived and returns to basal levels (Knott et al., 2002). However, there is also evidence for an earlier learning-related increase in inhibition (Cui et al., 2008). Regardless of the specific timing of the inhibitory change, our data suggest that learning induces an intrinsic change in pyramidal neurons (reduced postburst AHP) that allows them to readily participate in the neural network of information flow across brain regions. With formation of memory, the neural circuitry has to be maintained in check to prevent over excitation of the neural network and to allow selective information flow (i.e., reduce hyper-excitability and selectively filter information throughput). Our data suggest that this latter phase is established by increasing the inhibitory tone in the network, and thus, establishing the appropriate balance of the neural network involved in learning and memory.

The results reported here add to our understanding of the role of inhibitory interneurons within the hippocampus during the learning process, as well as confirming the physiological relevance of increased intrinsic excitability and expanding it to inhibitory neurons. However, we have directly examined only a specific subset of the wide variety of inhibitory interneurons located in the hippocampus. It is likely that learning also alters function of other interneuron types. Future experiments using newly discovered methodologies, e.g., optogenetics to control the activity of specific interneurons such as the O-LM interneurons (Leão et al., 2012), are necessary to determine which specific type of interneuron(s) is essential for successful learning. In addition, systematic examination of intrinsic membrane properties, including the postburst AHP, of the identified interneuron(s) is necessary to identify the cellular mechanism(s) that underlie learning that may be shared by both interneurons and pyramidal neurons. Our findings emphasize that the role of changes in excitatory synapses must be considered in relation to those occurring in inhibitory synapses to understand the function of the entire hippocampal circuit.

\section{References}

Berger TW, Alger B, Thompson RF (1976) Neuronal substrate of classical conditioning in the hippocampus. Science 192:483-485. CrossRef Medline

Brosh I, Barkai E (2009) Learning-induced enhancement of feedback inhibitory synaptic transmission. Learn Mem 16:413-416. CrossRef Medline

Buzsáki G (2002) Theta oscillations in the hippocampus. Neuron 33:325340. CrossRef Medline

Christian KM, Thompson RF (2003) Neural substrates of eyeblink conditioning: acquisition and retention. Learn Mem 10:427-455. CrossRef Medline

Cui Y, Costa RM, Murphy GG, Elgersma Y, Zhu Y, Gutmann DH, Parada LF,
Mody I, Silva AJ (2008) Neurofibromin regulation of ERK signaling modulates GABA release and learning. Cell 135:549-560. CrossRef Medline

Disterhoft JF, Oh MM (2006) Learning, aging and intrinsic neuronal plasticity. Trends Neurosci 29:587-599. CrossRef Medline

Disterhoft JF, Coulter DA, Alkon DL (1986) Conditioning-specific membrane changes of rabbit hippocampal neurons measured in vitro. Proc Natl Acad Sci U S A 83:2733-2737. CrossRef Medline

Farley SJ, McKay BM, Disterhoft JF, Weiss C (2011) Reevaluating hippocampus-dependent learning in FVB/N mice. Behav Neurosci 125: 871-878. CrossRef Medline

Freund TF, Buzsáki G (1996) Interneurons of the hippocampus. Hippocampus 6:347-470. Medline

Fuchs EC, Zivkovic AR, Cunningham MO, Middleton S, Lebeau FE, Bannerman DM, Rozov A, Whittington MA, Traub RD, Rawlins JN, Monyer H (2007) Recruitment of parvalbumin-positive interneurons determines hippocampal function and associated behavior. Neuron 53:591-604. CrossRef Medline

Han JH, Kushner SA, Yiu AP, Cole CJ, Matynia A, Brown RA, Neve RL, Guzowski JF, Silva AJ, Josselyn SA (2007) Neuronal competition and selection during memory formation. Science 316:457-460. CrossRef Medline

Han JH, Kushner SA, Yiu AP, Hsiang HL, Buch T, Waisman A, Bontempi B, Neve RL, Frankland PW, Josselyn SA (2009) Selective erasure of a fear memory. Science 323:1492-1496. CrossRef Medline

Kaczorowski CC, Sametsky E, Shah S, Vassar R, Disterhoft JF (2011) Mechanisms underlying basal and learning-related intrinsic excitability in a mouse model of Alzheimer's disease. Neurobiol Aging 32:1452-1465. CrossRef Medline

Klausberger T, Somogyi P (2008) Neuronal diversity and temporal dynamics: the unity of hippocampal circuit operations. Science 321:53-57. CrossRef Medline

Knott GW, Quairiaux C, Genoud C, Welker E (2002) Formation of dendritic spines with GABAergic synapses induced by whisker stimulation in adult mice. Neuron 34:265-273. CrossRef Medline

Leão RN, Mikulovic S, Leão KE, Munguba H, Gezelius H, Enjin A, Patra K, Eriksson A, Loew LM, Tort AB, Kullander K (2012) OLM interneurons differentially modulate CA3 and entorhinal inputs to hippocampal CA1 neurons. Nat Neurosci 15:1524-1530. CrossRef Medline

Lopez de Armentia M, Jancic D, Olivares R, Alarcon JM, Kandel ER, Barco A (2007) cAMP response element-binding protein-mediated gene expression increases the intrinsic excitability of CA1 pyramidal neurons. J Neurosci 27:13909-13918. CrossRef Medline

Maccaferri G, McBain CJ (1996) The hyperpolarization-activated current (Ih) and its contribution to pacemaker activity in rat CA1 hippocampal stratum oriens-alveus interneurones. J Physiol 497:119-130. Medline

Markram H, Toledo-Rodriguez M, Wang Y, Gupta A, Silberberg G, Wu C (2004) Interneurons of the neocortical inhibitory system. Nat Rev Neurosci 5:793-807. CrossRef Medline

Maviel T, Durkin TP, Menzaghi F, Bontempi B (2004) Sites of neocortical reorganization critical for remote spatial memory. Science 305:96-99. CrossRef Medline

McBain CJ, Fisahn A (2001) Interneurons unbound. Nat Rev Neurosci 2:11-23. CrossRef Medline

McEchron MD, Disterhoft JF (1997) Sequence of single neuron changes in CA1 hippocampus of rabbits during acquisition of trace eyeblink conditioned responses. J Neurophysiol 78:1030-1044. Medline

McEchron MD, Disterhoft JF (1999) Hippocampal encoding of non-spatial trace conditioning. Hippocampus 9:385-396. CrossRef Medline

McKay BM, Oh MM, Galvez R, Burgdorf J, Kroes RA, Weiss C, Adelman JP, Moskal JR, Disterhoft JF (2012) Increasing SK2 channel activity impairs associative learning. J Neurophysiol 108:863-870. CrossRef Medline

Minneci F, Janahmadi M, Migliore M, Dragicevic N, Avossa D, Cherubini E (2007) Signaling properties of stratum oriens interneurons in the hippocampus of transgenic mice expressing EGFP in a subset of somatostatin-containing cells. Hippocampus 17:538-553. CrossRef Medline

Oh MM, Power JM, Thompson LT, Disterhoft JF (2000) Apamin increases excitability of CA1 hippocampal pyramidal neurons. Neurosci Res Comm 27:135-142. CrossRef

Oh MM, McKay BM, Power JM, Disterhoft JF (2009) Learning-related postburst afterhyperpolarization reduction in CAl pyramidal neurons is 
mediated by protein kinase A. Proc Natl Acad Sci U S A 106:1620-1625. CrossRef Medline

Oliva AA Jr, Jiang M, Lam T, Smith KL, Swann JW (2000) Novel hippocampal interneuronal subtypes identified using transgenic mice that express green fluorescent protein in GABAergic interneurons. J Neurosci 20: 3354-3368. Medline

Poolos NP, Migliore M, Johnston D (2002) Pharmacological upregulation of h-channels reduces the excitability of pyramidal neuron dendrites. Nat Neurosci 5:767-774. Medline

Power JM, Thompson LT, Moyer JR Jr, Disterhoft JF (1997) Enhanced synaptic transmission in CA1 hippocampus after eyeblink conditioning. J Neurophysiol 78:1184-1187. Medline

Ruediger S, Vittori C, Bednarek E, Genoud C, Strata P, Sacchetti B, Caroni P (2011) Learning-related feedforward inhibitory connectivity growth required for memory precision. Nature 473:514-518. CrossRef Medline

Stocker M, Krause M, Pedarzani P (1999) An apamin-sensitive $\mathrm{Ca}^{2+}$ activated $\mathrm{K}^{+}$current in hippocampal pyramidal neurons. Proc Natl Acad Sci U S A 96:4662-4667. CrossRef Medline
Urban-Ciecko J, Kossut M, Mozrzymas JW (2010) Sensory learning differentially affects GABAergic tonic currents in excitatory neurons and fast spiking interneurons in layer 4 of mouse barrel cortex. J Neurophysiol 104:746-754. CrossRef Medline

Wu WW, Chan CS, Disterhoft JF (2004) Slow afterhyperpolarization governs the development of NMDA receptor-dependent afterdepolarization in CA1 pyramidal neurons during synaptic stimulation. J Neurophysiol 92:2346-2356. CrossRef Medline

Zhang L, McBain CJ (1995) Potassium conductances underlying repolarization and after-hyperpolarization in rat CA1 hippocampal interneurones. J Physiol 488 (Pt 3):661-672.

Zhou Y, Won J, Karlsson MG, Zhou M, Rogerson T, Balaji J, Neve R, Poirazi P, Silva AJ (2009) CREB regulates excitability and the allocation of memory to subsets of neurons in the amygdala. Nat Neurosci 12:1438-1443. CrossRef Medline 